$P_{1}$

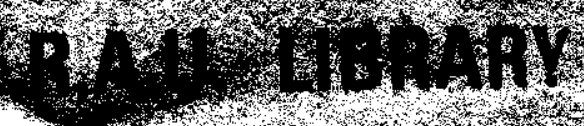

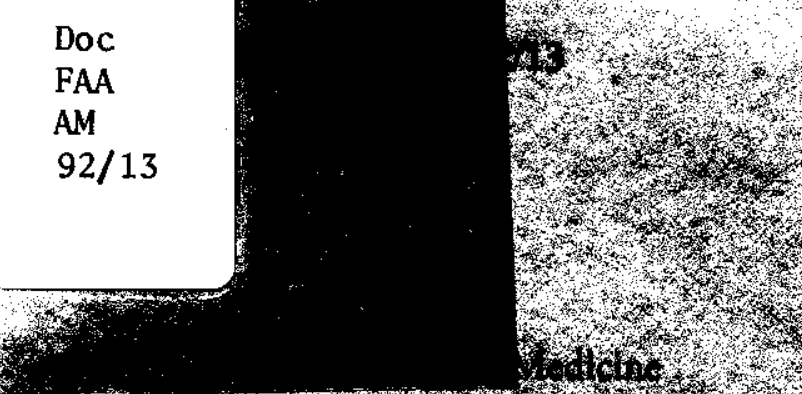

Warnin $1,6261 \%$

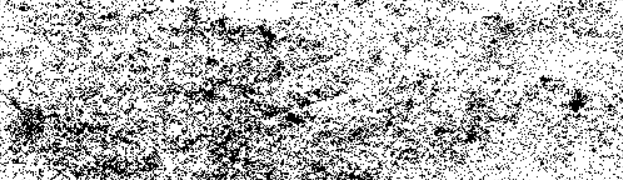

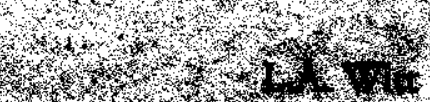

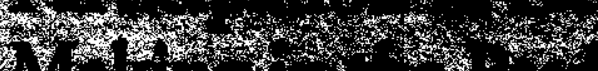 .}

o.

\section{ghar Nullowin:}

G. 1 .



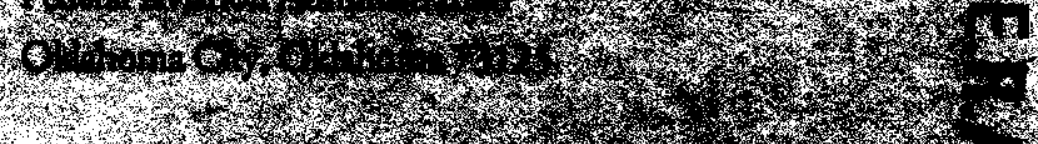

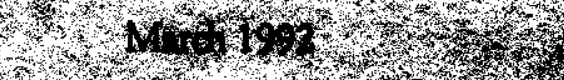
4.7 .7 .7$.

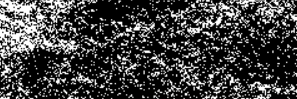
$4^{3} y^{3} y^{3}$ t.t. 1.t.

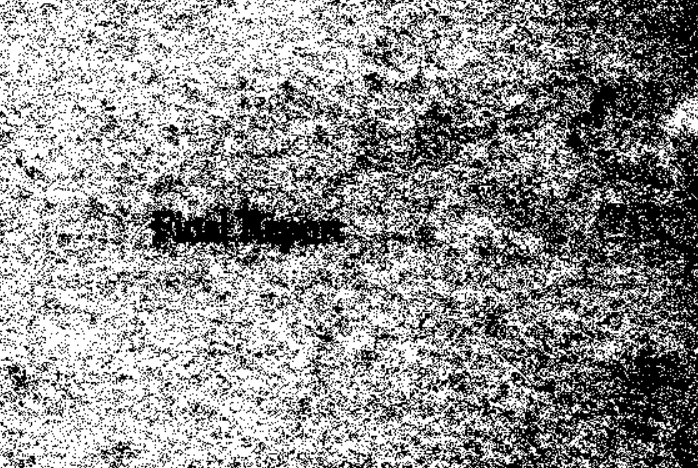
$3 x+2$

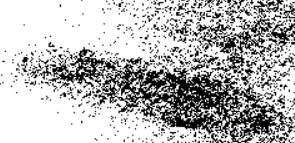

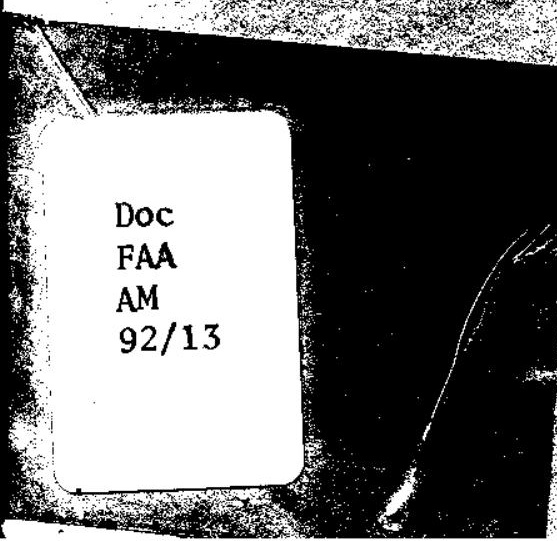

1.1. T.t.

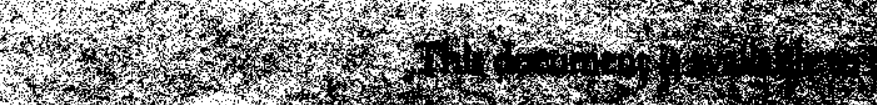
a axtse

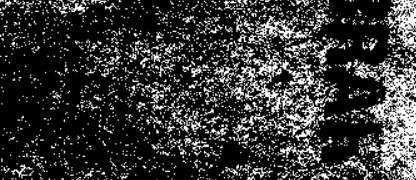
, 4.

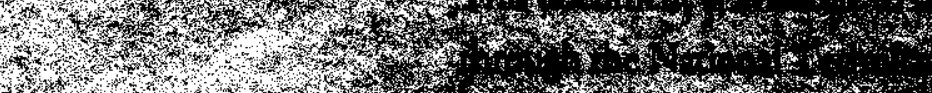

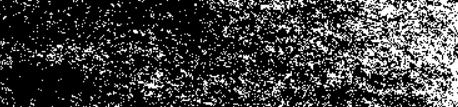
S6.

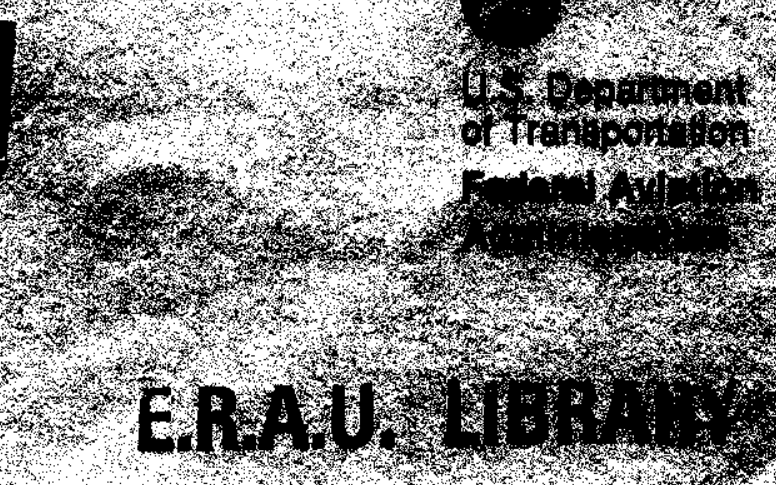
t. 5 . r t.t.

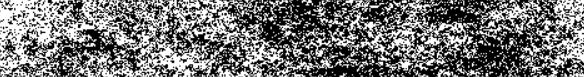
3. 


\begin{tabular}{|c|c|c|}
\hline $\begin{array}{l}\text { 1. Report No. } \\
\text { DOT/FAA/AM-92/13 }\end{array}$ & 2. Government Accession No. & 3. Recipient's Catalog No. \\
\hline \multirow{2}{*}{\multicolumn{2}{|c|}{$\begin{array}{l}\text { 4. Title and Subtitle } \\
\text { EFFECTS OF SUBORDINATE FEEDBACK TO THE SUPERVISOR } \\
\text { AND PARTICIPATION IN DECISION-MAKING IN THE } \\
\text { PREDICTION OF ORGANIZATIONAL SUPPORT }\end{array}$}} & 5. Report Date March 1992 \\
\hline & & 6. Performing Organization Code \\
\hline \multicolumn{2}{|l|}{$\begin{array}{l}\text { 7. Author's) } \\
\text { L. A. Witt, and Chan Hellman }\end{array}$} & 8. Performing Organization Report No. \\
\hline \multirow{2}{*}{\multicolumn{2}{|c|}{$\begin{array}{l}\text { 9. Porforming Organization Name and Address } \\
\text { FAA Civil Aeromedical Institute } \\
\text { P. O. Box } 25082 \\
\text { Oklahoma City, OK } 73125\end{array}$}} & 10. Work Unit No. (TRAIS) \\
\hline & & 11. Contract or Grant No. \\
\hline 12. Sponsoring Agency Name and Address & & 13. Type of Report and Period Covered \\
\hline $\begin{array}{l}\text { Office of Aviation Medicine } \\
\text { Federal Aviation Administration } \\
800 \text { Independence Avenue, S.W. } \\
\text { Washington, D.C. } 20591\end{array}$ & & 14. Sponsoring Agency Code \\
\hline
\end{tabular}

This work was performed under task AM-C-92-HRR-122.

16. Abstract

The present study tested the hypotheses that participation in decision-making (PDM) and perceived effectiveness of subordinate feedback to the supervisor would contribute unique variance in the prediction of perceptions of organizational support. In line with concerns for dispositional affect as a contributor to method variance and the possibility that biodata may explain some of the effects of PDM and feedback on support, dispositional affect and biodata variables were included in the analyses. Hierarchical regression analyses, conducted on data collected from 1,083 federal government workers, indicated that both feedback and PDM added unique variance to the prediction of support. These findings have implications for both management and research.

\begin{tabular}{|c|c|c|c|}
\hline \multirow[b]{2}{*}{$\begin{array}{l}\text { 17. Koy Words } \\
\text { Subordinate Feedback } \\
\text { Participation } \\
\text { Decision-making } \\
\text { Organizational Support }\end{array}$} & \multicolumn{3}{|c|}{ 18. Distribution Statement } \\
\hline & & \multicolumn{2}{|c|}{$\begin{array}{l}\text { Document is available to the } \\
\text { public through the National } \\
\text { Technical Information Service, } \\
\text { Springfield, Virginia } 22161\end{array}$} \\
\hline 19. Security Classif. (of this report) & 20. Security Clossif. (of this page) & 21. No. of Poges & 22. Price \\
\hline Unclassified & Unclassified & 10 & \\
\hline
\end{tabular}




\section{EFFECTS OF SUBORDINATE FEEDBACK TO THE SUPERVISOR AND PARTICIPATION IN DECISION-MAKING IN THE PREDICTION OF ORGANIZATIONAL SUPPORT}

In their development of the construct of perceived organizational support, Eisenberger, Huntington, Hutchison, and Sowa (1986) suggested that employees are more inclined to commitment and satisfaction when they feel that their organization values their input and cares about their well-being. They found that employees form global beliefs concerning the extent to which the organization is supportive of them and that perceived organizational support is related to increased commitment and innovation and reduced absenteeism (Eisenberger et al., 1986; Eisenberger, Fasolo, \& Davis-LaMastro, 1990). The present study tested the hypotheses that participation in decision-making and perceived effectiveness of subordinate feedback to the supervisor would contribute to perceptions of organizational support.

\section{PARTICIPATION IN DECISION-MAKING}

As noted by Witt (1992), the outcomes of increased worker participation in decision-making (PDM) have been of theoretical and practical interest for several years. Argyris (1964) argued that workers will manifest responsible adult behaviors only when their managers realize that they want to be involved in making decisions. Indeed, "psychological folklore" (Greenberg \& Folger, 1983, p. 235) suggests that PDM will generally have positive outcomes. Although empirical investigations of the effects of PDM have yielded mixed results (cf. Cotton, Vollrath, Froggatt, Lengnick-Hall, \& Jennings, 1988), a number of positive outcomes have been identified, including increased organization information-processing capabilities (Castrogiovanni \& Macy, 1990), job attitudes (Argyris, 1964), employee health (Jackson, 1983), and understanding work tasks (Niehoff, Enz, \& Grover, 1990).

Dachler (1978) suggested that inadequate and differing definitions of PDM have caused problems for PDM researchers. Thibaut and Walker (1975) conceptualized two forms of participation: (a) choice, where the participant has some control over the outcome, and (b) voice, where the participant articulates his/her interest to the decision-maker. Voice may include influence over defining the problem, gathering information bearing on the decision, and identifying alternatives, but not making the decision (Thibaut \& Walker, 1975). Cohen (1985) argued that to the extent that subordinates can express opinions to the supervisor, they have a "voice."

We suggest that both voice and choice reflect PDM. When subordinates make decisions without discussions with the supervisor, they are acting autonomously and essentially have choice, but they are making decisions without the supervisor's voice. In our view, this reflects a low level of PDM, as does the situation when decisions are made by the supervisor without discussion, where the subordinate has neither choice nor voice. Two moderate levels of PDM occur when: (a) the supervisor usually makes the decisions following discussion, as both have voice but the subordinate usually has little choice; and (b) the subordinate generally makes the decision after discussion, as both have choice and voice (the supervisor has choice, because he/she permitted the subordinate to make the decision). However, it may be likely that the supervisor did not engage the issue if the subordinate usually makes the decision. However, when they discuss issues and reach a decision based on consensus (i.e., a collaboration to find resolution), both have optimal voice and choice, which we consider to be a high level of PDM.

Based on this conceptual definition of low, moderate, and high levels of PDM, we hypothesized that higher levels of PDM would be associated with perceptions of greater organizational support. Employees who actively engage in discussions about important issues with their supervisors and who, as a result, develop a consensus to resolve the issues might perceive greater support from the organization than employees who make the decisions or whose supervisors make decisions for them. Indeed, such a joint decision provides joint ownership, which may generate positive consequences down the line. This notion is consistent with Baumgartel's 
(1957) report that employee performance, job satisfaction, and positive attitudes toward the supervisor were higher among employees whose supervisors engaged in participation, were lowest among employees whose supervisors directed activities with no discussion, and were intermediate among employees whose supervisors who took a laissez faire (subordinate decides) approach.

\section{SUBORDINATE FEEDBACK TO THE SUPERVISOR}

The appropriateness and utility of subordinate feedback to the supervisor have been issues of practical concern for many years (e.g., Bowers \& Franklin, 1975). Carroll and Schneier (1982) suggested that performance appraisals of supervisors generated by subordinates have the advantages of providing opportunities for employee participation, for the supervisors to enhance their effectiveness, and for team building between subordinates and supervisors. They also noted the disadvantage of subordinate fear of either reprisal or apathy from a supervisor upon receiving the feedback results. In a study of subordinate survey feedback to supervisors, Rosebush and Tallarigo (1991) found that subordinate feedback increased both supervisory and work unit effectiveness.

If employees perceive a supervisor to be receptive to their feedback, and, when appropriate, to act in a manner consistent with their feedback, they may be likely to perceive organizational support, in contrast to employees who perceive their supervisor as defensive, negative, or apathetic toward feedback. In line with this notion, we hypothesized that the perceived effectiveness of subordinate feedback to the supervisor would be positively related to perceptions of organizational support. Although perceived organizational support reflects what the "organization" provides to the employee, the response of the supervisor to the subordinate's feedback is conceptually relevant to organizational support. As some or much of the subordinate's feedback may be designed to direct the supervisor's behavior toward facilitating the subordinate's work efforts, the supervisor's response to the feedback can affect the subordinate's view of the support that he/she is receiving.

\section{AFFECT AND THE PROBLEM OF METHOD VARIANCE}

The notion of method variance (Podsakoff \& Organ, 1986) suggests that collecting data with a single type of measurement leads to an artificially inflated relationship between the constructs measured, because the ratings for each individual may share a single information processing and dispositional basis. Implicit in this argument is the notion that individual disposition influences the relationships of interest. A problem in assessing method variance has involved identifying the disposition that underlies job attitudes and then measuring the operationalized disposition. Recent advances in the affect literature provide means of approaching a resolution to this problem.

In studies of self-reported mood, negative affect (NA) and positive affect (PA) consistently have emerged as the two dominant and relatively independent dimensions (Diener \& Emmons, 1985). Watson and Clark (1984) argued that the tendency to experience negative or positive affect reflects a stable, ongoing disposition. They stated (p. 483) that "high-NA individuals are more likely to report distress, discomfort, and dissatisfaction over time and regardless of the situation, even in the absence of any overt or objective source of stress." Overall, these individuals focus on their disappointments, shortcomings, and mistakes, adopting a more negative view of life experiences. Low-NA persons, on the other hand, tend to be more self-secure, satisfied, and calm, focusing less on daily frustrations and adopting a more resilient approach to setbacks. Watson and Clark (1984) stressed that dispositional NA represents subjective differences in temperament, mood, and cognitive orientation rather than an index of psychological health. They suggested that individuals high in PA are characterized by high energy, full concentration, and pleasurable engagement, whereas low-PA individuals typically experience sadness and lethargy.

Staw, Bell, and Clausen (1986, p. 61) argued that employees "bring a positive or negative disposition to the work setting, process information about the job in a way that is consistent with that disposition, and then experience job satisfac- 
tion or dissatisfaction as a result." Indeed, it is likely that PA and NA may confound the development of job attitudes. Perceptions of situational factors that contribute variance beyond that of dispositional affect may reflect situational effects and not mere method variance.

\section{THE PRESENT STUDY}

Following the literature cited above, the primary purpose of the present study was to test the hypothesis that participation in decisionmaking and the perceived effectiveness of subordinate feedback to the supervisor would contribute unique variance to the prediction of perceptions of organizational support. Given the often assumed and sometimes demonstrated importance of biodata in the prediction of job attitudes (see, for example, Brush, Moch, \& Pooyan, 1987), we entered biographical variables into the equation. In line with concerns for dispositional affect as a contributor to method variance, we also included PA and NA scores in the analyses. By entering dispositional affect into the equation after the biodata, but before the PDM and feedback components, we could determine whether or not they added variance beyond that already contributed by biodata. The primary hypothesis was that feedback and PDM would add variance over-and-above the variance contributed by both biodata and affect.

\section{METHOD}

\section{Subjects and Procedure}

Questionnaires were mailed to the 2,103 employees of the Mike Monroney Aeronautical Center. One thousand eighty-three (53.8\%) employees (61.5\% males and $38.5 \%$ females) returned completed questionnaires by mail. Included were biodata items assessing minority status, age, tenure, supervisory status, education, and salary. About $20 \%$ of the responding employees classified themselves as members of a minority racial group. Respondent ages were: ages 17 to $29(7.9 \%), 30$ to $39(23.0 \%), 40$ to $49(39.0 \%), 50$ to $59(26.6 \%)$ and $60+$ years (3.5\%). Responses to an item assessing years in the organization at the current site were: less than one year $(12.1 \%), 1$ to 3 years $(25.9 \%), 4$ to 10 years $(26.0 \%), 11$ to 15 years $(14.6 \%)$, and 16 or more years of service (21.4\%). Supervisory status reported by the respondents were: non-supervisor $(86.6 \%)$, supervisor $(9.5 \%)$, and manager $(3.9 \%)$. The sample was relatively well educated: 12 years or less of formal education $(12.9 \%), 13$ to 15 years $(51.7 \%), 16$ years $(24.5 \%)$, and 17 or more years $(10.9 \%)$. Salary within the federal government is based upon grade level. Responses to the grade level item were: grade levels 1 to $4(12.0 \%)$, grade levels 5 to $7(19.2 \%)$, grade levels 8 to $10(9.4 \%)$, grade levels 11 to $13(43.3 \%)$, and grade levels $14+(16.1 \%)$.

\section{Measures}

Support was assessed by the Eisenberger et al. (1986) 16-item short form of the Survey of Perceived Organizational Support $(\alpha=.95, M$ $=50.35, S D=14.27$ ). This scale measures a general perception employees have concerning the extent to which the organization values their contributions and well-being. Items were presented on a 5-point Likert-type scale $(1=$ strongly disagree; $2=$ inclined to disagree; $3=$ neither disagree nor agree; $4=$ inclined to agree; and $5=$ strongly agree). High scores reflect perceptions of greater support.

Participation in decision-making $(\alpha=.90, M$ $=10.77, S D=4.21$ ) was examined by six items asking respondents to indicate "what best describes the way you and/or your immediate supervisor make decisions about:" (a) "your performance appraisal review," (b) "most things," (c) "communicating information outside your work unit," (d) "overall work activities of your work unit," (e) "what your job duties will be," and (f) "how or when you will get your work done." These items were presented on a 5-point Likert-type scale ( $1=$ "we discuss things a great deal and come to a decision based on consensus regarding the issue at hand;" 2 = "we discuss things a great deal, and his/her decision is usually adopted;" 3 = "we discuss things a great deal, and my decision is usually adopted;" $4=$ "we don't discuss things very much, and his/her decision is usually adopted;" and $5=$ "we don't discuss things very much, and I make most of the decisions"). Items 4 and 5 were 
recoded as a 1 , responses 2 and 3 were recoded as a 2 , and response 1 was recoded as a 3 . The six items and their means and standard deviations are presented in Table 1. A sum of the responses was computed to provide a total PDM score. High scores reflect perceptions of greater PDM.

Feedback was assessed by a single item ( $M=$ 2.78, $S D=1.28$ ) based on Rosebush and Tallarigo's (1991) work on the effects of subordinate feedback. This item measures the employees' perceptions of the effect of their feedback on their supervisor's behavior. Employees were asked, "When you give your immediate supervisor feedback about how he/she is doing," and responded on a 5 -point, Likert-type scale $(1=$ "I do not attempt to give feedback;" $2=$ "He/she never really listens to me when I try to give feedback;" $3=$ "He/she listens to me and then his/her behavior occasionally reflects what I have said;" $4=$ = He/she listens to me and then his/her behavior usually reflects what I have said;" and $5=$ "He/she listens and then his/her behavior reflects what I have said").

Positive and negative affect were assessed by the Watson, Clark, and Tellegen (1988) PANAS scale based upon their earlier research indicating that the experience of positive or negative affect represents a stable, ongoing dispositional trait (c.f. Watson \& Clark, 1984; Watson et al., 1988). This scale consists of a 10-item Positive Affect Scale $(\alpha=.89, M=36.04, S D=7.12)$ and a 10 -item Negative Affect Scale $(\alpha=.86$, $M=16.22, S D=5.7)$, respectively. The PANAS scale measures to what extent the respondent generally perceives him/herself to experience certain feelings. Results reported by Watson et al. (1988) suggest that these measures assess dispositional affect that may be independent of situational influences in which the measure is taken. Response options were presented on a 5-point, Likert-type scale $(1=$ very slightly or not at all; $2=$ a little; $3=$ moderately; $4=$ quite a bit; and $5=$ extremely). High scores indicate high PA and NA.

\section{TABLE 1}

\section{PDM Items}

1. To what extent do you and/or your immediate supervisor make decisions about your performance appraisal review? $(M=1.63, S D=.81)$

2. To what extent do you and/or your immediate supervisor make decisions about most things? $(M=1.94, S D=.90)$

3. To what extent do you and/or your immediate supervisor make decisions about communicating information outside your work unit? $(M=1.84, S D=.87)$

4. To what extent do you and/or your immediate supervisor make decisions about overall work activities of your work unit? $(M=1.85, S D=.87)$

5. To what extent do you and/or your immediate supervisor make decisions about what your job duties will be? ( $M=$ $1.80, S D=.86)$

6. To what extent do you and/or your immediate supervisor make decisions about how or when you will get your work done? $(M=1.70, S D=.85)$

\section{TABLE 2}

\section{Intercorrelation Matrix}

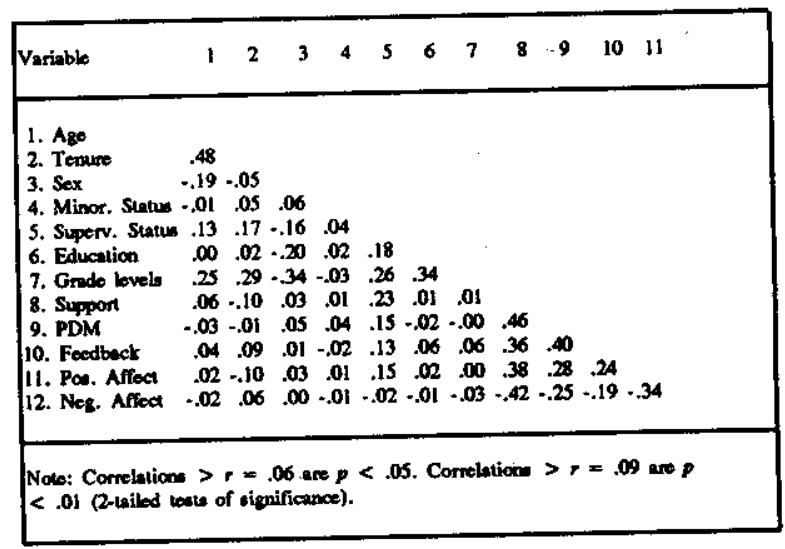




\section{RESULTS}

The intercorrelation matrix is presented in Table 2. As shown there, the biodata variables (sex, minority vs. non-minority status, supervisory status, education, salary level, time in organization, and age) were very weakly related to perceptions of PDM, effects of subordinate feedback, and organizational support. However, PDM $(r=.46)$, feedback $(r=.36)$, PA $(r=$ .38 , and NA scores $(r=-.42)$ were significantly $(p<.01)$ related to support scores. PDM and feedback scores were also related $(r=.40, p$ $<.01)$.

We entered the biodata variables as a block into the equation predicting support scores. They accounted for a slight amount of variance $\left(\mathrm{R}^{2}=\right.$ $.06, F=8.8, p<.01$ ). We then entered positive and negative affect scores as one block into the equation. They added significant variance over-and-above the variance contributed by biodata $\left(\Delta \mathrm{R}^{2}=.22, F=143.0, p<.01\right)$. The biodata and dispositional variables accounted for a modest amount of the variance in support scores (total adjusted $\mathrm{R}^{2}=.27$ ).

In order to test the hypothesis that PDM practices accounted for unique variance over-and-above the biodata and dispositional variables, we entered PDM scores as a third predictor. We entered PDM prior to feedback, as it was more strongly correlated with support. The incremental variance was significant $\left(\Delta \mathrm{R}^{2}\right.$ $=.10, F=143.8, p<.01$ ). Finally, to test the hypothesis that perceptions of the effects of subordinate feedback would also add unique variance, we entered feedback scores as the fourth predictor into the equation. They contributed a slight but significant amount of variance $\left(\Delta \mathrm{R}^{2}=.02, F=28.9, p<.01\right)$ over-and-above the effects of the previously entered variables. The predictor variables accounted for a moderate amount of the variance in perceived organizational support scores (total adjusted $\left.\mathrm{R}^{2}=.39, F=55.6, p<.01\right)$.

\section{DISCUSSION}

We emphasize several caveats before discussing the results. First, the subjects most likely responded to the survey in one sitting; thus, these data may be subject to common method variance. However, our inclusion of PA and NA scores in the equations permitted some assessment of the contributions of PDM and feedback above the variance contributed by dispositional affect. Although these contributions were significant, the significant amount of the variance contributed by PA and NA supports arguments suggesting a dispositional basis for method variance. Second, the government employees sampled in the present study may not be representative, and replication in the private sector is needed. Third, these data were cross-sectional, and a longitudinal design might permit a more accurate assessment of job attitudes and dispositional affect. Despite these limitations, results of the regression analyses support our hypotheses that both the perceived effects of subordinate feedback to the supervisor and PDM contribute unique variance to the prediction of organizational support.

In addition, our definitions of low, moderate, and high levels within a continuum of PDM may be somewhat problematic. Individual and situational differences may lead certain types of PDM to be favored over others. For example, some employees may perceive an ideal PDM level to occur when the supervisor tells the employee, "You make the decision, and I'll support you."

Previous researchers (Bowers \& Franklin, 1975; Carroll \& Schneier, 1982; Rosebush \& Tallarigo, 1991) have concluded that subordinate feedback to the supervisor increases supervisor effectiveness and improves communication. Our data extend this literature, as they indicate that employees whose supervisors' behaviors reflect the subordinates' feedback perceive greater support from the organization. We emphasize that while feedback added only a modest amount of variance to the equation, it did so over-and-above the variance contributed by biodata, dispositional affect, and PDM.

As mentioned earlier, researchers have shown that PDM has a number of positive outcomes. The data presented here suggest that PDM also may lead to perceptions of greater organizational support. Indeed, it is not surprising that subor- 
dinates who collaborate with their supervisors to develop a consensus on resolving work-related issues may perceive greater support than employees who generally make decisions on their own or have decisions made for them.

\section{IMPLICATIONS FOR MANAGEMENT PRACTICE}

Nogradi and Koch (1981) argued that providing additional opportunities for decision-making for personnel who are involved in fewer than desired decisions is extremely important from an organizational perspective. They stressed (p. 157) that allowing "individuals to move toward a decisional equilibrium state must be a high priority for the manager." We suggest that PDM is not simply an issue of too little vs. too much decision-making. Rather, employees may perceive more support when their supervisors collaborate with them to make decisions -- a collaboration perhaps yielding a "joint ownership" that may provide political support for the decision and also protection to the employee when negative consequences come about. Indeed, our data are consistent with intuitive expectations that joint decisions are preferable to unilateral ones.

Although the importance of PDM as an antecedent of organizational outcomes has been empirically confirmed, some managers avoid PDM. Some managers may do so because they do not know how to collaborate with their workers, while others may explicitly decide to manage by mystery to keep their people unaware of events, and others may simply have not thought about alternative management styles. Alternatively, some managers may simply believe that they know best and see no need to engage in PDM. Whatever the reason, we suggest that our data and the growing PDM literature provide sufficient evidence to indicate that efforts to increase PDM (in appropriate situations) may lead to favorable outcomes. Our data suggest utility in the supervisor listening to subordinate feedback and, when appropriate, acting in a manner consistent with that feedback. Even though the relationships described here were not particularly robust, it is likely that higher levels of PDM and appropriate supervisor responses to subordinate feedback may have substantial utility, particularly in large organizations.

\section{REFERENCES}

Argyris, C. (1964). Integrating the individual and the organization. New York: Wiley.

Baumgartel, H. (1957). Leadership style as a variable in research administration. $A d$ ministrative Science Quarterly, 2, 344-360.

Bowers, D. G., \& Franklin, J. (1975). Survey guided development: Data based organizational change. Ann Arbor, MI: University of Michigan, Institute for Social Research.

Brush, D. H., Moch, M. K., \& Pooyan, A. (1987). Individual demographic differences and job satisfaction. Journal of Occupational Behaviour, 8, 139-156.

Carroll, S., \& Schneier, C. (1982). Performance appraisal and review systems: The identification, measurement, and development of performance in organizations. Glenview, IL: Scott, Foresman, \& Co.

Castrogiovanni, G. J., \& Macy, B. A. (1990). Organizational information-processing capabilities and degree of employee participation. Group and Organization Studies, 15, 313-336.

Cohen, R. L. (1985). Procedural justice and participation. Human Relations, 38, 643-663.

Cotton, J. L., Vollrath, D. A., Froggatt, K. L., Lengnick-Hall, M. L., \& Jennings, K. R. (1988). Employee participation: Diverse forms and different outcomes. Academy of Management Review, 13, 8-22.

Dachler, H. P. (1978). The problem nature of participation in organizations: A conceptual evaluation. In B. King, S. Sweufert, and F. E. Fiedler (Eds.), Managerial control and organization democracy (pp. 17-29). New York: John Wiley and Sons. 
Diener, E., \& Emmons, R. A. (1985). The independence of positive and negative affect. Journal of Personality and Social Psychology, 47, 1105-1117.

Eisenberger, R., Fasolo, P., \& Davis-LaMastro, V. (1990). Perceived organizational support and employee diligence, commitment, and innovation. Journal of Applied Psychology, $75,51-59$.

Eisenberger, R., Huntington, R., Hutchison, S., \& Sowa, D. (1986). Perceived organizational support. Journal of Applied Psychology, 71, 500-507.

Greenberg, J., \& Folger, R. (1983). Procedural justice, participation, and the fair process effect in groups and organizations. In P. Paulus (Ed), Basic group processes (pp. 235-256). New York: Springer-Verlag.

Jackson, E. E. (1983). Participation in decision-making as a strategy for reducing job-related strain. Journal of Applied Psychology, 68, 3-19.

Niehoff, B. P., Enz, C. A., \& Grover, R. A. (1990). The impact of top-management actions on employee attitudes and perceptions. Group and Organization Studies, 15, 337-352.

Nogradi, G. S., \& Koch, S. A. (1981). The relationship between decisional participation and commitment to the organization, community, and profession among municipal recreation administrators. Leisure Sciences, 4 , 143-159.
Podsakoff P. M., \& Organ, D. W. (1986). Self-reports in organizational research: Problems and prospects. Journal of Management, 12, 531-544.

Rosebush, M. A., \& Tallarigo, R. S. (1991, June). Assessments of the usefulness of subordinate survey feedback to supervisors. Presented at the Third Annual American Psychological Society Meeting. Washington, D.C.

Staw, B. R., Bell, N. E., \& Clausen, J. A. (1986). The dispositional approach to job attitudes: A lifetime longitudinal test. $\boldsymbol{A d}$ ministrative Sciences Quarterly, 31, 56-77.

Thibaut, J., \& Walker, L. (1975). Procedural justice: A psychological analysis. Hillsdale, NJ: Lawrence Earlbaum.

Watson, D., \& Clark, L. A. (1984). Negative affectivity: The disposition to experience aversive emotional states. Psychological Bulletin, 96, 465-490.

Watson, D., Clark, L. A., \& Tellegen, A. (1988). Development and validation of brief measures of positive and negative affect: The PANAS scales. Journal of Personality and Social Psychology, 54, 1063-1070.

Witt, L.A. (1992). Exchange ideology as a moderator of the relationships between importance of participation in decision-making and job attitudes. Human Relations, 45, 73-85.

*U.S.GPO : 1992-661-063/40041 